\title{
Comparison between male and female teachers in Egyptian primary schools regarding the effect of teaching on their voice
}

\author{
E. A. Zaky ${ }^{*}$ (D, H. Mamdouh, A. Maher and Z. Khalaf
}

\begin{abstract}
Background: Teachers are more likely to develop voice disorders compared to non-teachers in other occupations. Teachers are often cited as a high-risk group for vocal dysfunction as they use their voices extensively over their profession for instructing and managing students, also due to other extra loading factors, such as background noise, long speaking distance, poor room acoustics, and lack of adequate equipment, like voice amplifiers. The primary school teachers are particularly at risk as they have little opportunity for voice rest during the working day. Gender is another factor affecting incidence of voice disorders. Female teachers seem to be more affected by voice disorders than male teachers. The aim of our study was to compare between genders (male-female teachers) in primary schools to show the effect of teaching and other risk factors on their voice for proper management.

Results: The study showed that there were statistically significant differences between male teachers and female teachers regarding history of voice change; female teachers had history of voice change more than male teachers. Female teachers suffered from emotional stress more than male teachers, and this affects their voice. In addition, study showed a significant association between the grade of dysphonia and $\mathrm{VHI}$.

Conclusion: There is evidence that female teachers are complaining more of voice change and suffering from voice disorders than males. Besides, female teachers are showing a higher degree of emotional stress. This may necessitate a combined assessment of the voice and psychological profile of all teachers with voice change.
\end{abstract}

Keywords: Teachers, Female, Voice, Professional

\section{Background}

Although voice problems are very common and widely spread, it seems that certain occupational factors put vocal health at higher risk than others. First of those high-risk persons are professional voice users [1]. Schoolteachers are one of the largest groups who depend greatly on their voice for work [2]. For teachers, the voice is the main tool for the transmission of information to pupils; therefore, the voice must be flexible, resilient, and clear for efficient teaching [3]. In the teaching profession, there is heavy

* Correspondence: dr_efat_am@yahoo.com

Department of Otolaryngology, Phoniatrics Unit, Minia Faculty of Medicine, Minia University, Minia, Egypt

\section{Springer Open}

vocal loading due to misuse and abuse of voice and also due to other extra loading factors, such as long speaking distance, background noise, lack of adequate equipment, like voice amplifiers and poor room acoustics [4]. Yiu [5] described the impact of voice problems on teacher's social life, communication, personal emotions, and occupation. Moreover, voice symptoms, described as tired, difficulties in phonation, and change of voice qualities are very often associated with physical discomfort and disability, a health problem [6]. Ewis and Abo Haseeba [7] reported that being a female teacher increased the risk of developing dysphonia compared with male teachers. De Alvear and Martinez [8] reported that teachers become stressed when 
they feel that job demands are higher than their ability to cope with them. The attitudes of students toward teachers with dysphonia might increase their stress. Teachers who experience stress may deal with a vicious cycle: stress and anxiety contribute to voice problems and voice problems contribute to them [9].

This work aims to compare between genders (male-female teachers) in primary schools to show the effect of teaching and other risk factors on their voice for proper management.

\section{Methods}

\section{Sample size}

This study included two groups of subjects. Group I included 100 male teachers work at primary school, group II include 100 female teachers work at primary school with the average working hours per week ( $15 \mathrm{~h} /$ week) for both groups, age ranging from 25 years to 55 years. These subjects were taken from many primary schools in the El Minia Government; both groups were statistically matched in comparative data about sex distribution. Permission to enter schools was taken from the Directorate of Education; we have entered about 30 primary schools in different in our governorate.

\section{Methods}

Each individual of both groups was subjected to the following survey (survey is any activity that collects information in an organized and methodical manner about characteristics of interest from some or all units of a population using well-defined concepts, methods, and procedures, and compiles such information into a useful summary form) [10]. In our survey study, It was on a group of teachers (specific population) using the following data, patient interview and history taking, Auditory Perceptual Assessment (APA), and Voice Handicap Index VHI.

\section{Auditory Perceptual Assessment (APA)}

After careful listening to the patient's voice, the grade of dysphonia, character of voice, pitch changes, loudness, glottal attack, and affection of associated laryngeal functions could be determined using the modified GRBAS scale [11].

\section{The Voice Handicap Index VHI}

All patients filled The Voice Handicap Index VHI because they were literate. We used Malky et al. [12] Arabic of VHI; it underwent a series of reliability testing and is standardized for Arabic culture.

\section{Results}

The individuals in this study included in two groups:

Male teachers (GI): included 100 male teachers work at a primary school.
Female teachers (GII): included 100 female teachers work at a primary school.

\section{Demographic data}

There were non-statistically significant differences between male teachers (GI) and female teachers (GII) regarding the age (Table 1 ).

\section{Social factors}

A highly statistically significant differences were found between male teachers (GI) and female teachers (GII) regarding the number of weekly teaching hours to their children at home. There were non-statistically significant differences between male teachers GI and female teachers GII regarding the marital state, the number of children, and the age of their youngest children (Table 2).

\section{Classroom factors}

There were non-statistically significant differences between male teachers (GI) and female teachers (GII) regarding the teaching hours, the working years, and the mean number of students in class (Table 3).

\section{Complaint}

There were statistically significant differences between male teachers (GI) and female teachers (GII) regarding change of voice and phonasthenic symptoms (Table 4).

\section{Impact of complaint on teachers}

Statistically significant differences were obtained between male teachers (GI) and female teachers (GII) regarding the effect of voice change on daily life activity. In GI, 33 (33\%) male teachers had positive history of affection of their voice on daily life activity, while in GII, $47(47 \%)$ female teachers had positive history of affection of their voice on daily life activity. Statistically significant differences were obtained between male teachers (GI) and female teachers (GII) regarding positive history of listener's reaction. In GI, 31 (31\%) male teachers had positive history of listener's reaction, while 46 (46\%) female teachers had positive history of listener's reaction in GII (Table 5).

Table 1 Comparison between male and female teachers in age

\begin{tabular}{llll}
\hline & $\begin{array}{l}\text { Male (GI) } \\
(\boldsymbol{n}=100)\end{array}$ & $\begin{array}{l}\text { Female (GII) } \\
(\boldsymbol{n}=100)\end{array}$ & $\boldsymbol{P}$ value \\
\hline Age & & & 0.956 \\
Range & $(29-55)$ & $(28-55)$ & \\
Mean \pm SD & $41.3 \pm 6.3$ & $41.2 \pm 6.4$ & \\
Median & 40 & 40.5 &
\end{tabular}

Non-significant $(P \geq 0.05)$, significant $(P<0.05)$, highly significant $(P$ $<0.001$ ) 
Table 2 Comparison between male and female teachers regarding social factors

\begin{tabular}{lll}
\hline Data & $\begin{array}{l}\text { Male(Gl) } \\
(n=100)\end{array}$ & $\begin{array}{l}\text { Female(GII) } \\
(n=100)\end{array}$ \\
\hline Marital status & $5(5 \%)$ & $5(5 \%)$ \\
Not married & $95(95 \%)$ & $95(95 \%)$ \\
Married & & 1 \\
Number of children & $(0-5)$ & $(0-6)$ \\
Range & $2.29 \pm 1.1$ & $3 \pm 1$ \\
Mean \pm SD & $n 3$ & 3 \\
Median & & $(16-26)$ \\
Number of weekly teaching hours to their children at home & $(0-5)$ & $21.2 \pm 3$ \\
Range & $2.9 \pm 1.1$ & 22 \\
Mean \pm SD & 3 & $<.462$ \\
Median & & $(0-25)$ \\
Age of the youngest & $(0-25)$ & $8 \pm 5.3$ \\
Range & $8 \pm 5.4$ & 7 \\
Mean \pm SD & 7 & 0.948 \\
Median & & 7 \\
\hline
\end{tabular}

Non-significant $(P \geq 0.05)$, significant $(P<0.05)$, highly significant $(P<0.001)$

\section{Etiological factors}

Highly statistically significant differences were obtained between male and female teachers regarding smoking index. In GI, there were 70 (70\%) non-smokers, 15 (15\%) were mild smokers, $5(5 \%)$ were moderate smokers, $4(4 \%)$ were heavy smokers, $1(1 \%)$ was ex-smoker, and $5(5 \%)$ were Goza, while in GII, there were 99(99\%) non-smokers and $1(1 \%)$ was heavy smoker. Highly statistically significant differences were obtained between male teachers (GI) and female teachers (GII) regarding emotional stress. In GI, there was $1(1 \%)$ who suffered from emotional stress, while in GII, there were 15 (15\%) who suffered

Table 3 Comparison between male and female teachers regarding classroom factors

Non-significant $(P \geq 0.05)$, significant $(P<0.05)$, highly significant $(P<0.001)$ from mild stress and 5 (5\%) suffered from moderate stress. As regards medication, statistically significant differences were obtained between male teachers (GI) and female teachers (GII) $P$ value (0.002). In GI, there were $9(9 \%)$ male teachers who had history of drug intake in the form of anti-diabetic and antihypertensive. While in GII, there were 26 (26\%) female teachers had history of drug intake especially (oral contraceptive pills) (Table 6).

\section{Auditory Perceptual Assessment}

Statistically significant differences were observed between male teachers (GI) and female teachers (GII) regarding the grade of dysphonia $P$ value (0.031) (Table 7).

Table 4 Comparison between male and female teachers in change of voice phonasthenic symptoms

\begin{tabular}{llll}
\hline Data & $\begin{array}{l}\text { Male(GI) } \\
(\boldsymbol{n}=100)\end{array}$ & $\begin{array}{l}\text { Female(GII) } \\
(\boldsymbol{n}=100)\end{array}$ & $\boldsymbol{P}$ value \\
\hline $\begin{array}{llll}\text { Change of voice } \\
\text { Range }\end{array}$ & $(0-10)$ & $(0-10)$ & $\mathbf{0 . 0 1 5}^{*}$ \\
$\quad \begin{array}{l}\text { Mean } \pm \text { SD } \\
\quad \text { Median }\end{array}$ & $0.5 \pm 1.2$ & $1 \pm 1.9$ & \\
$\begin{array}{l}\text { Phonasthenic symptoms } \\
\text { No }\end{array}$ & 0 & 0 & $\mathbf{0 . 0 4 6 ^ { * }}$ \\
$\quad$ Yes & $64(64 \%)$ & $50(50 \%)$ & \\
\hline
\end{tabular}

Non-significant $(P \geq 0.05)$, significant $(P<0.05)$, highly significant $(P$ $<0.001$ ) 
Table 5 Comparison between male and female teachers in the impact of complaint on teachers

\begin{tabular}{llll}
\hline Data & $\begin{array}{l}\text { Male }(\mathrm{Gl}) \\
(\boldsymbol{n}=100)\end{array}$ & $\begin{array}{l}\text { Female (GII) } \\
(\boldsymbol{n}=100)\end{array}$ & $\boldsymbol{P}$ value \\
\hline Degree of severity & & & 0.100 \\
$\quad$ No & $66(66 \%)$ & $52(52 \%)$ & \\
Mild & $25(25 \%)$ & $28(28 \%)$ & \\
Moderate & $8(8 \%)$ & $17(17 \%)$ & \\
$\quad$ Severe & $1(1 \%)$ & $3(3 \%)$ & $\mathbf{0 . 0 4 3}$ \\
Effect on daily life & & & \\
$\quad$ Not affected & $67(67 \%)$ & $53(53 \%)$ & $\mathbf{0 . 0 2 9 *}$ \\
$\quad$ Affected & $33(33 \%)$ & $47(47 \%)$ & \\
Listener's reaction & & & \\
$\quad$ No & $69(69 \%)$ & $54(54 \%)$ & \\
Yes & $31(31 \%)$ & $46(46 \%)$ & \\
\hline
\end{tabular}

Non-significant $(P \geq 0.05)$, significant $(P<0.05)$, highly significant $(P$ $<0.001$ )
Voice Handicapped Index (VHI)

Statistical significant differences were observed between male teachers (GI) and female teachers (GII) regarding VHI physical handicap $(P=0.015)$ (Table 8$)$.

Results of the study revealed highly statistically significant positive correlation between degree of handicap of VHI (three subscales and total) and grade of dysphonia in the male group (Table 9).

Results of the study revealed highly statistically significant positive correlation between degree of handicap of VHI (three subscales and total) and grade of dysphonia in the female group (Table 10).

In female teachers (GII), results of the study revealed statistically significant positive correlation between voice change and emotional stress. In female teachers (GII), results of the study revealed highly statistically significant positive correlation between voice change and emotional handicap (Table 11)

\section{Discussion}

regarding etiological factors

\begin{tabular}{|c|c|c|c|}
\hline Data & $\begin{array}{l}\text { Male }(G I) \\
(\boldsymbol{n}=100)\end{array}$ & $\begin{array}{l}\text { Female (GII) } \\
(\boldsymbol{n}=100)\end{array}$ & $\boldsymbol{P}$ value \\
\hline Smoking index & & & $<0.001^{*}$ \\
\hline No & 70(70\%) & 99(99\%) & \\
\hline Mild & $15(15 \%)$ & $0(0 \%)$ & \\
\hline Moderate & $5(5 \%)$ & $0(0 \%)$ & \\
\hline Heavy & $4(4 \%)$ & $1(1 \%)$ & \\
\hline Goza & $5(5 \%)$ & $0(0 \%)$ & \\
\hline Ex-smoker & $1(1 \%)$ & $\mathrm{O}(0 \%)$ & \\
\hline Emotional stress & & & $<0.001^{*}$ \\
\hline Normal & 99(99\%) & $80(80 \%)$ & \\
\hline Mild & $1(1 \%)$ & $15(15 \%)$ & \\
\hline Moderate & $0(0 \%)$ & $5(5 \%)$ & \\
\hline Allergy & & & 0.831 \\
\hline No & 88(88\%) & $87(87 \%)$ & \\
\hline Yes & $12(12 \%)$ & $13(13 \%)$ & \\
\hline Reflux & & & 1 \\
\hline No & 95(95\%) & 95(95\%) & \\
\hline Yes & $5(5 \%)$ & $5(5 \%)$ & \\
\hline Medication & & & $0.002^{*}$ \\
\hline No & $91(91 \%)$ & $74(74 \%)$ & \\
\hline Yes & $9(9 \%)$ & $26(26 \%)$ & \\
\hline Surgery & & & 0.621 \\
\hline No & 98(99\%) & 97(97\%) & \\
\hline Yes & $1(1 \%)$ & $3(3 \%)$ & \\
\hline
\end{tabular}

Nerrière et al. [13] reported that one in two female teachers reported voice disorders (50.0\%) compared to one in four males (25.0\%). Also, Munier and Kinsella [13] stated that school teachers are at risk as they have little opportunity for voice rest during the working day. Teachers of the junior classes were more vulnerable to develop a change of voice than those of senior classes. We observed highly statistically significant differences between male teachers (GI) and female teachers (GII) regarding the number of weekly teaching hours to their children at home. This result may be explained by the fact that women more often care for children at home, which may involve a considerable additional vocal load in the form of screaming and shooting, and this result agrees with Vilkman [14]. In our study, there were statistically significant differences between male teachers (GI) and female teachers (GII) regarding the change of voice. Dysphonia was 33\% in male teachers while it was $48 \%$ in female teachers. We would predict that schoolteachers are the largest groups who depend on their voice for instructing and managing students, leading to extra use of voice and vocal problems. Female teachers with high risk for developing voice changing compared with male teachers due to female teachers in our study have been noticed as talkative, vocally aggressive, emotionally disturbed, and elevated levels of voice use inside and outside the home. At home, they care for children, and this is an additional factor for vocal loading. Students usually fear the anger of a male teacher than a female one. Therefore, controlling the noise and disordered classes is a difficult task for a female teacher who uses her voice at a 
Table $\mathbf{7}$ Comparison between male and female teachers in Auditory Perceptual Assessment

\begin{tabular}{|c|c|c|c|}
\hline & $\begin{array}{l}\text { Male (GI) } \\
(\boldsymbol{n}=100)\end{array}$ & $\begin{array}{l}\text { Female (GII) } \\
(\boldsymbol{n}=100)\end{array}$ & $\boldsymbol{P}$ value \\
\hline Grade of dysphonia & & & $0.031^{*}$ \\
\hline 0 & $62(62 \%)$ & $41(41 \%)$ & \\
\hline I & $30(30 \%)$ & $42(42 \%)$ & \\
\hline$|-| \mid$ & $1(1 \%)$ & $4(4 \%)$ & \\
\hline$\|$ & $6(6 \%)$ & $11(11 \%)$ & \\
\hline$\|-\|$ & $0(0 \%)$ & $1(1 \%)$ & \\
\hline III & $1(1 \%)$ & $1(1 \%)$ & \\
\hline Leaky & & & 0.185 \\
\hline 0 & $76(76 \%)$ & $61(61 \%)$ & \\
\hline I & $17(17 \%)$ & $24(24 \%)$ & \\
\hline$|-| \mid$ & $1(1 \%)$ & $2(2 \%)$ & \\
\hline$\|$ & $5(5 \%)$ & $11(11 \%)$ & \\
\hline$\|-I\|$ & $0(0 \%)$ & $1(1 \%)$ & \\
\hline III & $1(1 \%)$ & $1(1 \%)$ & \\
\hline Strained & & & 0.145 \\
\hline 0 & 79(79\%) & $68(68 \%)$ & \\
\hline । & $18(18 \%)$ & $21(21 \%)$ & \\
\hline$|-| \mid$ & $0(0 \%)$ & $2(2 \%)$ & \\
\hline$\|$ & $3(3 \%)$ & $8(8 \%)$ & \\
\hline$\|-\| \|$ & $0(0 \%)$ & $0(0 \%)$ & \\
\hline III & $0(0 \%)$ & $1(1 \%)$ & \\
\hline Irregular & $84(84 \%)$ & & 0.203 \\
\hline 0 & $15(15 \%)$ & $73(73 \%)$ & \\
\hline । & $1(1 \%)$ & $24(24 \%)$ & \\
\hline$|-| \mid$ & $0(0 \%)$ & $3(3 \%)$ & \\
\hline$\|$ & $0(0 \%)$ & $0(0 \%)$ & \\
\hline$\|-\| \|$ & & $0(0 \%)$ & \\
\hline \multicolumn{4}{|l|}{ III } \\
\hline Pitch & & & $0.016^{*}$ \\
\hline Normal & $61(61 \%)$ & $44(44 \%)$ & \\
\hline Decrease & 39(39\%) & $56(56 \%)$ & \\
\hline Register & & & 0.683 \\
\hline Modal & $98(98 \%)$ & $96(96 \%)$ & \\
\hline Break & $2(2 \%)$ & $3(3 \%)$ & \\
\hline Fry & $0(0 \%)$ & $1(1 \%)$ & \\
\hline Falsetto & $0(0 \%)$ & $0(0 \%)$ & \\
\hline Loudness & & & - \\
\hline Affected & $0(0 \%)$ & $0(0 \%)$ & \\
\hline Normal & $100(100 \%)$ & $100(100 \%)$ & \\
\hline Glottal attack & & & - \\
\hline Not hard & $100(100 \%)$ & $100(100 \%)$ & \\
\hline Hard & O(0\%) & $0(0 \%)$ & \\
\hline Laryngeal function & & & 0.086 \\
\hline
\end{tabular}


Table 7 Comparison between male and female teachers in Auditory Perceptual Assessment (Continued)

\begin{tabular}{lll}
\hline & $\begin{array}{l}\text { Male (GI) } \\
(\boldsymbol{n}=100)\end{array}$ & $\begin{array}{l}\text { Female (GII) } \\
(\boldsymbol{n}=100)\end{array}$ \\
\hline Not affected & $64(64 \%)$ & $52(52 \%)$ \\
Affected & $36(36 \%)$ & $48(48 \%)$ \\
\hline
\end{tabular}

Non-significant $(P \geq 0.05)$, significant $(P<0.05)$, highly significant $(P<0.001)$

maximum volume to control the students and to overcome a loud and misbehaved class environment. Moreover, using loud voices during their teaching, which could be attributed to a large number of students per class, as the average estimated number of students in a class is 50 , and up to a maximum of 60 . Many studies are consistent with our results as Ewis and Abo Haseeba [7]. Also, De Jong et al. [15] found that female teachers were twice as likely as male teachers to develop voice problems. Also, they reported that one in two female teachers and one in four males were complaining of voice disorders, and females were more susceptible to suffer from voice disorder.

Statistically significant differences were obtained between male teachers (GI) and female teachers (GII) regarding phonasthenic symptoms. Phonasthenia was 36\% in male teachers while it was $50 \%$ in female teachers. This result can be explained as most of the female teachers were complaining of tiredness or effort when speaking, throat clearing or persistent coughing, the sensation of tightness or weight in the throat, voice breaks, breathlessness when speaking, aphonia, soreness or burning in the throat, and change in voice, and this result agreed with Simberg et al. [16]. In addition, Smith et al. [17] found that

Table 8 Comparison between male and female teachers in VHI

\begin{tabular}{|c|c|c|c|}
\hline Data & $\begin{array}{l}\text { Male }(G I) \\
(\boldsymbol{n}=100)\end{array}$ & $\begin{array}{l}\text { Female (GII) } \\
(\boldsymbol{n}=100)\end{array}$ & $\boldsymbol{P}$ value \\
\hline VHI functional & & & 0.188 \\
\hline $\begin{array}{l}\text { Normal } \\
\text { Mild } \\
\text { Moderate } \\
\text { Severe }\end{array}$ & $\begin{array}{l}79(79 \%) \\
4(4 \%) \\
6(6 \%) \\
11(11 \%)\end{array}$ & $\begin{array}{l}67(67 \%) \\
3(3 \%) \\
11(11 \%) \\
19(19 \%)\end{array}$ & \\
\hline VHI physical & & & $0.012^{*}$ \\
\hline $\begin{array}{l}\text { Normal } \\
\text { Mild } \\
\text { Moderate } \\
\text { Severe }\end{array}$ & $\begin{array}{l}80(80 \%) \\
6(6 \%) \\
6(6 \%) \\
8(8 \%)\end{array}$ & $\begin{array}{l}66(66 \%) \\
4(4 \%) \\
5(5 \%) \\
25(25 \%)\end{array}$ & \\
\hline VHI emotional & & & $0.015^{*}$ \\
\hline $\begin{array}{l}\text { Normal } \\
\text { Mild } \\
\text { Moderate } \\
\text { Severe }\end{array}$ & $\begin{array}{l}75(75 \%) \\
9(9 \%) \\
11(11 \%) \\
5(5 \%)\end{array}$ & $\begin{array}{l}69(69 \%) \\
5(5 \%) \\
7(7 \%) \\
19(19 \%)\end{array}$ & \\
\hline VHI total & & & 0.164 \\
\hline $\begin{array}{l}\text { Normal } \\
\text { Mild } \\
\text { Moderate } \\
\text { Severe }\end{array}$ & $\begin{array}{l}78(78 \%) \\
7(7 \%) \\
5(5 \%) \\
10(10 \%)\end{array}$ & $\begin{array}{l}66(66 \%) \\
6(6 \%) \\
8(8 \%) \\
20(20 \%)\end{array}$ & \\
\hline
\end{tabular}

Non-significant $(P \geq 0.05)$, significant $(P<0.05)$, highly significant $(P$ $<0.001$ ) female teachers reported a higher frequency of phonasthenic symptoms than males (38 vs. $26 \%$ ) and more absence from work due to voice complaints (a ratio of 1.64).

Statistically significant differences were obtained between male teachers (GI) and female teachers (GII) regarding the effect of voice change on daily life activity. In GI, 33\% of male teachers had a positive history of affection of their voice on daily life activity, while it was $47 \%$ in female teachers. This result may be explained by the change of voice in female teachers were higher than male teachers and female teachers were complaining from phonasthenic symptoms more than male teachers. This lead to missing working days, decreased the number of phone calls they made, increased their vocal loudness to compensate voice change that interferes with students' perception and learning experience, reduced social ability, and felt that their emotional state was influenced. Many studies are consistent with our result as Ma and Yiu [18], who showed that the quality of life refers to the functioning of individuals in daily activities and individual's participation in these activities: reduction of job satisfaction, communicative ability, social ability, and emotional stability for teachers. Van Houtte et al. [19] reported that vocal dysphonia leads to a lesser quality of teaching and increased absence. In addition, Anderson [20] mentioned that teachers have to increase their speaking loudness level to maintain speech intelligibility and teaching efficiency in a classroom because the background noise is almost as loud as the teacher's voice. Sheng et al. [21] also reported that there were many more teachers are using microphones in the classroom after they began experiencing a change of voice.

In addition, Smith et al. [17] found that female teachers reported a higher frequency of phonasthenic symptoms than males (38 vs. $26 \%$ ), and more absence from work due to voice complaints (a ratio of 1.64).

Table 9 Correlation between $\mathrm{VHI}$ and grade of dysphonia in male teachers

\begin{tabular}{|c|c|c|c|c|}
\hline \multirow[t]{3}{*}{$\overline{\mathrm{VHI}}$} & \multicolumn{4}{|c|}{ Male(Gl) } \\
\hline & \multicolumn{2}{|c|}{ Degree of handicap } & \multicolumn{2}{|c|}{ Grade of dysphonia } \\
\hline & $R$ & $\boldsymbol{P}$ value & $\bar{R}$ & $\boldsymbol{P}$ value \\
\hline Functional & 0.608 & $<0.001^{*}$ & 0.594 & $<0.001^{*}$ \\
\hline Physical & 0.664 & $<0.001 *$ & 0.682 & $<0.001 *$ \\
\hline Emotional & 0.597 & $<0.001^{*}$ & 0.548 & $<0.001 *$ \\
\hline Total & 0.663 & $<0.001^{*}$ & 0.667 & $<0.001^{*}$ \\
\hline
\end{tabular}


Table 10 Correlation between VHI and grade of dysphonia in female teachers

\begin{tabular}{|c|c|c|c|c|}
\hline \multirow[t]{3}{*}{$\overline{\mathrm{VHI}}$} & \multicolumn{4}{|c|}{ Female (GII) } \\
\hline & \multicolumn{2}{|c|}{ Degree of severity } & \multicolumn{2}{|c|}{ Grade of dysphonia } \\
\hline & $\bar{R}$ & $\boldsymbol{P}$ value & $\bar{R}$ & $\boldsymbol{P}$ value \\
\hline Functional & 0.662 & $<0.001^{*}$ & 0.577 & $<0.001^{*}$ \\
\hline Physical & 0.691 & $<0.001^{*}$ & 0.614 & $<0.001^{*}$ \\
\hline Emotional & 0.710 & $<0.001^{*}$ & 0.598 & $<0.001 *$ \\
\hline Total & 0.724 & $<0.001 *$ & 0.640 & $<0.001 *$ \\
\hline
\end{tabular}

Statistically significant differences were obtained between male teachers (GI) and female teachers (GII) regarding the positive history of the listener's reaction. It was $31 \%$ in male teachers while it was $46 \%$ in female teachers. Our result can be explained by that vocal complaint in teachers are likely related to difficulty in producing natural voice and leading to avoid speaking with friends, neighbors, and relatives, and increase teacher's emotional stress. Listener noticed the change of voice of the speaker, and in our result, change of voice in female teachers was higher than male teachers, dysphonia in female teachers more than male teachers, and change in pitch more in female teachers than male ones. Our result goes with Assuncao and Oliveira [22], who found that dysphonia is manifested in different ways, such as voice loss, change of voice, phonasthenic symptoms, and lack of voice projection.

In our study, 33 male teachers had a history of voice change, 30 male teachers were a smoker and complaining from dysphonia, and 3 male teachers only had dysphonia are a non-smoker. In comparison to 48 , female teachers had a history of voice change, with only one female teacher was smoker complaint from voice change, and this explained that the smoker was the main cause for dysphonia in male teachers. This result in agreement with Simberg et al. [23] who reported that smoking has generally been seen as a primary cause for voice disorders and documented that smoking adversely affects the epithelium of the vocal folds and causes several kinds of lesions in the airways. The vocal musculature is strongly influenced by anxiety. During the emotional stress and anxiety, high levels of muscular tension in the organs involved in voice production may eventually lead to a change of voice. The psychogenic factors might cause voice disorders by increasing tension in the laryngeal muscles, especially for hyperfunctional dysphonia. Stress and tension play an important role in the development of dysphonia in professional voice users. In our study, highly statistically significant differences were obtained between male teachers (GI) and female teachers (GII) regarding emotional stress. Fifteen percent of female teachers suffered from mild stress, and 5 suffered from moderate stress. This result may be explained by that female teachers were noticed to be easily nervous, unable to inhibit or control their emotional reactions, and they were more vulnerable to life stresses more than male teachers. They become stressed when feeling that job demands are higher than their ability to cope with them, and the attitudes of students toward teachers with dysphonia might increase their stress. In addition, stress lead to habitual throat clearing, which is also harmful to the vocal folds. Many studies are consistent with our result as Shoeib et al. [24] who found that stress and tension play an important role in the development of dysphonia in professional voice users. Alves et al. [25] found that female teachers are at high risk of developing dysphonia. In addition, Smith et al. [9] reported that teachers who experience stress might deal with a vicious cycle between stress and anxiety and voice problems and voice problems. Kotby et al. [26] found that anxiety and stressful life events were highly significant among patients with phonasthenia, and this indicates that the psychological background is participating in the etiology of the condition and maybe the main causes as in conversion

Table 11 Correlation between voice changes and medication: weekly teaching hours to children at home; age of the youngest; emotional factor and stress; emotional VHI in female teachers

\begin{tabular}{lll}
\hline Females (GII) & Voice change \\
\cline { 2 - 3 }$N=100$ & $\boldsymbol{R}$ & $\boldsymbol{P}$ value \\
\hline Medication & 0.024 & 0.815 \\
Weekly teaching hours to their children at home & 0.090 & 0.371 \\
Age of the youngest & -0.024 & 0.815 \\
Emotional factor and stress & $\mathbf{0 . 2 9 9}$ & $\mathbf{0 . 0 0 3 ^ { * }}$ \\
Emotional VHI & $\mathbf{0 . 6 0 7}$ & $\mathbf{0 . 0 0 1 ^ { * }}$ \\
\hline
\end{tabular}


hysteria, and that reflects that the psychiatric therapy is mandatory in cases of phonasthenia regulation of the menstrual cycle is interactions of chemical messengers and hormones, of which estrogen and progesterone are the principal sex steroids. With the beginning of the menstrual cycle, the follicular phase is marked by increased amounts of estrogen and lower levels of progesterone. The combination of hormones is responsible for causing vocal fold edema and increased blood flow to the structures. The hormones regulating the menstrual cycle lead to a transient change of the true vocal fold vibratory characteristics before, during, or after menstruation. In our study, female teachers complained of a strained, weak voice, increased vocal fatigue, decreased range, and loss of vocal power and high harmonics during the menstruation period. This result agreed with Amir et al. [27] and Sameep et al. [28] who reported that progesterone promotes sloughing of the laryngeal epithelium and works against proliferation. It also makes the glandular secretions more viscous, leading to a decrease in vibratory efficiency and possibly increased cell damage. And Schneider et al. [29] found that the lower amount of estrogen also causes a breakdown in their connective tissues, precluding optimal vocal health. Silverman and Zimmer [30] reported that the impact of these hormone fluctuations during menses is greater in occupational voice users versus nonoccupational voice users. Chernobelsky [31] suggested that vocal fold changes during menses in non-optimal voice use or even vocal misuse (e.g., excessive vibration, poor vocal hygiene, inadequate breath management) may exacerbate the effect of menstruation on the voice. Also, Raj et al. [32] documented that the negative effects of menopause on the female voice perceptually and acoustically, supporting the positive effects of estrogen on voice quality in post-menopausal women.

Statistically significant differences were observed between male teachers (GI) and female teachers (GII) regarding the grade of dysphonia $P$ value (0.031). In GI, 38 (38\%) male teachers had dysphonia while in (GII), $59(59 \%)$ female teachers had dysphonia. This result may be explained by that female teachers were complaining from voice change more than male teachers due to female teacher misuse and abuse her voice inside and outside the home. Female was emotionally disturbed more than male. This result in agreement with Ewis and Abo Haseeba [7], who reported that being a female teacher increased the risk for change of voice compared with male teachers and Rusell et al. [33] reported that female teachers seem to be more affected by voice disorders than male teachers.

Statistically significant differences were observed between male teachers (GI) and female teachers (GII) regarding pitch. In GI, 39 (39\%) male teachers had decreased pitch, while in GII, 56(56\%) female teachers had a low pitch. This result may be explained by the change of voice in female teachers which were higher than male teachers; female teachers were suffering from dysphonia than male teachers, and the primary reason for the gender difference in pitch is vocal fold length and thickness, and the primary mechanism for pitch control is the variation in elongation of the vocal folds. Female vocal folds have been shown to have less tensile stress than a male. This result in agreement with Hunter et al. [34] who reported that the female vocal fold significantly less stiff during equal elongation or strain. The female tissue might require a larger percent elongation to obtain an equivalent stiffness range and thus an equivalent pitch range. This difference would require increased effort and, likely, more fatigue. Also, Titze [35] reported that the female vocal folds are, on average, $60 \%$ shorter anteroposterior diameter, which is one of the important reasons for women's higher average fundamental frequency (F0) (female 190 $\mathrm{Hz}$ versus male $120 \mathrm{~Hz}$ ). This difference in F0 may increase women's risk for voice disorders.

In our results, there were statistically significant differences in the scores of the emotional domain and physical domain of VHI between both groups, which were higher in female teachers (GII) in comparison with male teachers (GI). This result may be explained that there were many factors affecting voice change in both groups. In male teachers (GI), smoking is the main factor that affects vocal fold function. But in female teachers (GII), voice change due to several factors emotional stress, care of her children voice abuse, and misuse inside and outside the home. Our results revealed a highly statistically significant positive correlation between the grade of dysphonia and VHI. These results were explained that dysphonia is hypothesized to be a reliable reflection of the degree of voice handicap. The more severe is the degree of dysphonia; the more difficult for people to hear, the more restriction in joining the conversation with the resultant emotional effects on the individual himself. This is in agreement with Ghandour et al. [36], who found a significant correlation between VHI scores and the degree of dysphonia. Besides, Kooijman et al. [37] stated that VHI is used to measure the influence of voice problems on one's quality of life and offers unique information for the multidimensional diagnostics of dysphonia.

In female teachers (GII), our results revealed a statistically significant positive correlation between voice changes and emotional stress. This can be explained by that stress factors can produce a disturbance of voiceonly if their duration, frequency, and strength exceed the level of capability of the individual to overcome. The occurrence of other stress symptoms might correlate with the occurrence of muscle tension in the larynx. This result in agreement with Yiu [5] who stated that female teachers with dysphonia presented a higher level of psychological distress than the normal population, Lee 
et al. [38] reported that a significant number of female teachers with voice impairment as a chronic source of stress, anxiety, or frustration. There was a relationship between voice problems and the degree of anxiety, and the effect of these problems on the patient's life.

In female teachers (GII), our results revealed a highly statistically significant positive correlation between voice change and emotional handicap. This result may be explained by Stephanie et al. [39] in their study reported that the severity of psychosocial distress and vocal handicap were positively related. And this results in agreement with Wan [40], who found a significant correlation between voice impairment and emotional statuses such as anxiety, stress, and emotional exhaustion. Also, our result agreed with Shoeib et al. [24] who reported in their study that there was a significant association between the patient's self-evaluation of his voice handicap and anxiety state and such a high association advocates for both vocal education programs and psychiatric consultations.

\section{Conclusion}

There is evidence that female teachers are more complaining of voice change and suffering from voice disorders than males. Besides, female teachers are showing a higher degree of emotional stress. This may necessitate a combined assessment of the voice and psychological profile of all teachers with voice change. It is recommended in this study to reduce the number of students per class, reducing daily teaching hours, and the classrooms should be equipped and suitable for teaching with loudspeakers inside.

\section{Abbreviations}

VHI: Voice Handicap Index; APA: Auditory Perceptual Assessment

\section{Acknowledgements}

Not applicable

\section{Authors' contributions}

EAZ and HM. conceived of the presented idea. EAZ and HM. developed the theory and performed the computations. AM and ZK verified the analytical methods. HM and AM encouraged EAZ and HM to investigate [a specific aspect] and supervised the findings of this work. All authors discussed the results and contributed to the final manuscript. HM carried out the experiment. HM wrote the manuscript with support from ZK helped supervise the project. EAZ conceived the original idea. HM. developed the theoretical formalism, performed the analytic calculations and performed the numerical simulations. Both EAZ and HM authors contributed to the final version of the manuscript. ZK supervised the project. The author(s) read and approved the final manuscript.

\section{Funding}

No funding was obtained for this study.

\section{Availability of data and materials}

All data generated or analyzed during this study are included in this published article [and its supplementary information files].

\section{Ethics approval and consent to participate}

This study was approved by the ethics committee of Minia University Hospital, Faculty of medicine Egypt and the Egyptian Network of Research Ethics Committees ENREC. (Faculty Council Approval Date: 23rd January 2017). All patients participate in this research gave a written consent to participate within this research.

\section{Consent for publication}

Not applicable

\section{Competing interests}

The authors declare that they have no competing interests.

Received: 19 June 2020 Accepted: 25 August 2020

Published online: 17 November 2020

\section{References}

1. Sataloff RT (2001) Professional voice users: the evaluation of voice disorders. Occup Med 16(4):633-647

2. Verdolini K, Ramig LO (2001) Review occupational risks for voice problems. Logoped Phoniatr Vocol 26:37-46

3. Sylvia H, Jennifer M, Oates A, Suzanne C (2015) Voice problems in New Zealand Teachers: A National Survey. J Voice 29(5):645-655

4. Vilkman E (2001) A survey on the occupational safety and health arrangements for voice and speech professionals in Europe. In: Dejonckere PH (ed) Occupational voice - care and cure. Kugler Publications, The Hague, pp 129-138

5. Yiu EM (2002) Impact and prevention of voice problems in the teaching profession: embracing the consumers' view. J Voice 16(2):215-228

6. Hamdan AH, Sibai AM, Srour ZM (2007) Voice disorders in teachers: the role of family physicians. Saudi Med J 28:422-428

7. Ewis AA, Abo Haseeba A (2013) Occupational dysphonia among schoolteachers in Beni Suef Governorate, Egypt. Egypt J Occup Med 37:1-18

8. De Alvear RB, Martınez AG (2009) Teachers' voice disorders collateral effects Otorynolaryngologia 8:129-135

9. Smith E, Lemke J, Taylor M, Kirchner HL, Hoffman H (1998) Voice problems among teachers: difference by gender and teaching characteristics. J Voice 12:328-334

10. Ivan PF (2003) Survey methods and practices, Statistics Canada, Catalogue no. 12-587-X, ISBN 978-1-100:19-20

11. Kotby MN (1986) Voice disorders; recent diagnostic advances. Egypt J Otolaryngol 3:69-98

12. Malky KH, Mesallam AT, Farahat M, Bukhari M (2010) Validation and cultural modification of Arabic voice handicap. Eur Arch Otorhinolaryngol 267:1743-1175

13. Nerrière E, Vercambre MN, Gilbert F, Masféty V (2009) Voice disorders and mental health in teachers: a cross-sectional nationwide study. BMC Public Health 9:370-376

14. Vilkman E (2000) Voice problems at work: a challenge for occupational safety and health arrangement. Folia Phoniat ET Logop 52:120-125

15. De Jong Fl, Kooijman PG, Thomas G, Huinck WJ (2006) Epidemiology of voice problems in Dutch teachers. Folia Phoniatr Logop 58:186-198

16. Simberg S, Sala E, Rönnemaa A (2004) A comparison of the prevalence of vocal symptoms among teacher students and other university students. J Voice 18(3):363-368

17. Smith E, Gray SD, Dove H, Kirchner L, Heras H (1997) Frequency and effects of teachers' voice problems. J Voice 11:81-87

18. Ma EP, Yiu EM (2001) Voice activity and participation profile: assessing the impact of voice disorders on daily activities. J Speech Lang Hear Res 44: 511-524

19. Van Houtte E, Claeys S, Wuyts F, Van Lierd K (2011) the impact of voice disorders among teachers: vocal complaints, treatment-seeking behavior, knowledge of vocal care, and voice-related absenteeism. J Voice 25:570-575

20. Anderson K (2004) The problem of classroom acoustics: the typical classroom soundscape is a barrier to learning. Semin Hear 25:117-129

21. Chen SH, Chiang SC, Chung Y, Hsiao L, Hsiao KY (2010) Risk factors and effects of voice problems for teachers. J Voice 24:183-192

22. Assuncao E, Oliveira D (2009) Work intensification and teachers' health. Educ Soc 30:349-372

23. Simberg S, Hanna UD, Santtila P (2015) Gender differences in the prevalence of vocal symptoms in smokers. J Voice 29:588-591 
24. Shoeib RM, Nassar JF, Ghandour HH (2012) Anxiety in female teachers with dysphonia: correlation between the voice handicap index and anxiety state. Egypt J Otolaryngol 28:142-148

25. Alves LA, Robazzi CC, Marziale MP, de Felippe AN, Romano CC (2009) Health Disorders and teachers' voices: a workers' health issue. Rev Latino-Am Enfermagem 17:566-572

26. Kotby MN, Baraka M, El Sady SR, Ghanem M, Shoeib R (2003) Psychogenic stress as a possible etiological factor in non-organic dysphonia. Int Congr Ser. 1240:1251-1256

27. Amir O, Shental T, Shabtai E (2006) Birth control pills and nonprofessional voice: acoustic analyses. J Speech Lang Hear Res 49:1114-1126

28. Sameep K, Carlson D, Robert T, Sataloff F (2013) The Effect of Hormones on the Voice. J Sing 69:571-574

29. Schneider B, van Trotsenburg M, Hanke G, Bigenzahn W, Huber J (2004) Voice impairment and menopause. Menopause 11:151-158

30. Silverman EM, Zimmer CH (1978) Effect of the menstrual cycle Newman Preliminary report on hormone receptors in the human vocal fold, pp 55-78

31. Chernobelsky SI (2002) A study of menses-related changes to the larynx in singers with voice abuse. Folia Phoniatr Logop 54:2-7

32. Raj A, Gupta B, Chowdhury A, Chadha S (2010) A study of voice changes in various phases of menstrual cycle and in postmenopausal women. J Voice 24:363-368

33. Rusell A, Oates J, Greenwood KM (1998) Prevalence of voice problems in teachers. J Voice 12:467-479

34. Hunter EJ, Smith ME, Tanner K (2011) Gender differences affecting vocal health of women in vocally demanding careers. Logoped Phoniatr Vocol 36:128-136

35. Titze IR (1989) Physiologic and acoustic differences between male and female voices. J Acoust Soc Am 85:1699-1707

36. Ghandour H, Nassar J, Shoeib R (2007) Correlation between voice handicap index scores and both acoustic measures and grade of dysphonia in nonorganic voice disorders. Sci J Az Med Fac (girls) 28:559-568

37. Kooijman P, Thomas G, Graamans K, de Jong F (2007) Psychosocial impact of the teacher's voice throughout the career. J Voice 21:316-324

38. Lee SY, Lao XQ, Yu IT (2010) A cross-sectional survey of voice disorders among primary school teachers in Hong Kong. J Occup Health 52:344-352

39. Stephanie M, Liza M, Carol B, Peterson PA (2015) Correlation between the voice handicap index and anxiety state. J Voice 28:20-23

40. Wan CC (1999) Correlation of voice problems and emotional status in teachers. The University of Hong Kong 14 May

\section{Publisher's Note}

Springer Nature remains neutral with regard to jurisdictional claims in published maps and institutional affiliations.

\section{Submit your manuscript to a SpringerOpen ${ }^{\circ}$ journal and benefit from:}

- Convenient online submission

- Rigorous peer review

- Open access: articles freely available online

- High visibility within the field

- Retaining the copyright to your article

Submit your next manuscript at $\boldsymbol{\nabla}$ springeropen.com 